\title{
Arabic Culture as a Defensive Strategy: Tunisian Education as an Example
}

\author{
Boutheina Khaldi \\ American University of Sharjah, United Arab Emirates \\ bkhaldi@aus.edu
}

\begin{abstract}
Since independence, the educational system in the Arab world in general, and Tunisia in particular, has continued to alienate itself from the mainstream society. Deeply rooted in a colonial past, education has failed to effect social, economic, and political change. this paper focuses on the status of education, and by extension Arabic language, in Post-independent Tunisia. Using Pierre Bourdieu's theory of Cultural Reproduction, and Antonio Gramsci's theory of Cultural Hegemony. The method used is descriptive; to describe the research topic problems qualitatively to draw conclusions objectively according to primary data. The historical method is analyzing past events, interpreting them, and presenting the results to highlight their present and future effects. The finding sets out to argue that educational institutions are sites of power play.
\end{abstract}

Keywords: Arabic Language; Culture; Tunisia; Reform; Symbolic Power

المقدمة

يُعدّ موضوع إصلاح التعليم من المواضيع المفصلية التي شغلت الدول العربية منذ مهذ

الاستقلال- إن لم يكن قبله. وقد ظل النقاش حول المسألة سياسيا بحتاً وأحدَ الرهانات

الحاسمة في منحى تطور الصراع السياسي والاجتماعي والثقافي والهوياتي الذي يعكس تبايناً

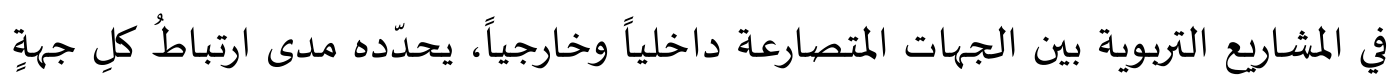

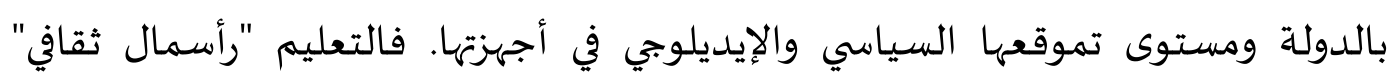

و"عنف رمزي" (Bourdieu, 2007) تمارسُهما الطبقة المهيمنة سعياً منها لتأبيد سلطتها

الرمزية (سلطة المركز) وترسيخ شرعيتها في مقابل إقصاء الطبقات الاجتماعية الدنيا

وعند التساؤل: هل تبحثُ الثقافة عن أمنها، نُواجـه ما يبدو تناقضياً صريحاً للوهلة

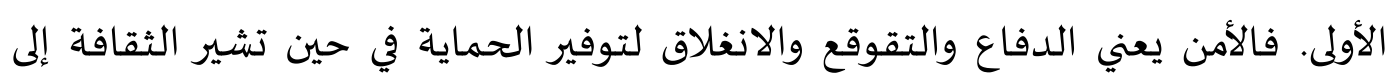
الانفتاح على الآخر والتفاعل والتحرر من كل القيود. 
أروم في هذه الدراسة أن أرصد واقع التعليم في تونس وأبين العلاقة بين الأمن

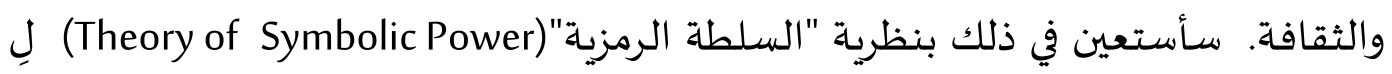
Antonio .Gramsci Jِ Organic Intellectual ونظرية (المثقف العضوي) Pierre Bourdieu

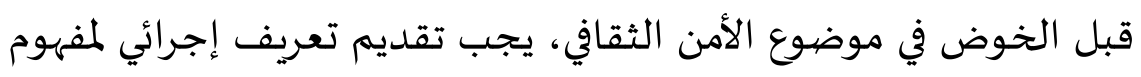

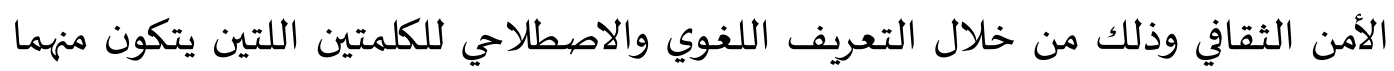

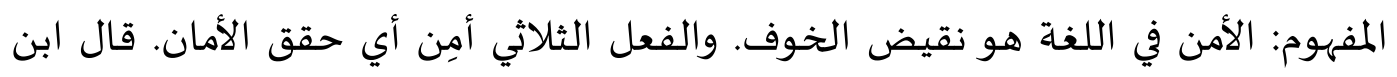

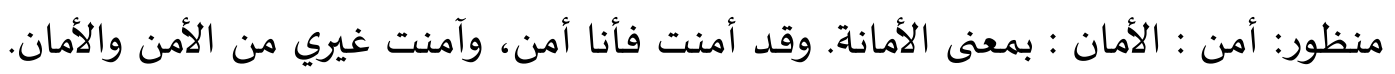

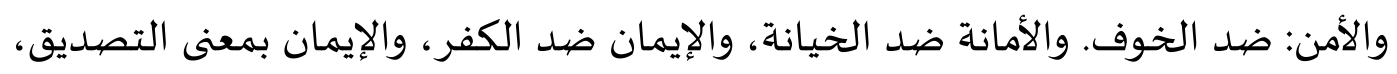

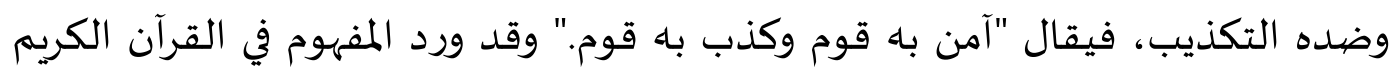

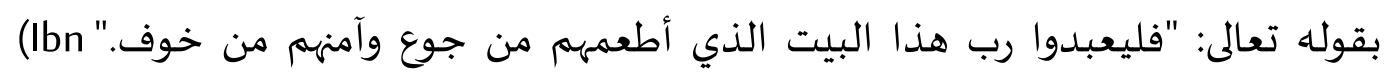
Manz̧ur)

يعود استخدام مصطلح الأمن إلى نهاية الحرب العالمية الثانية وإلى الدمار الذي

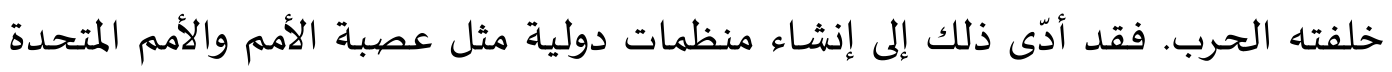

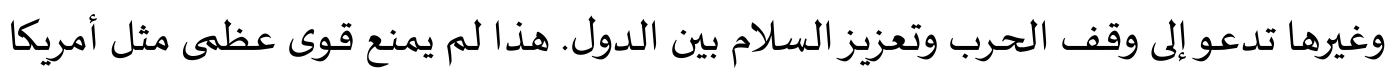

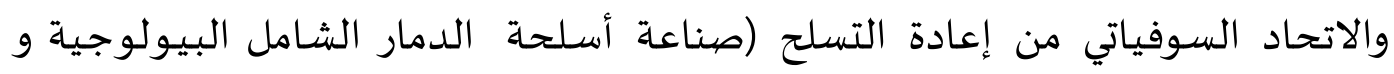
الكيميائية و الذرياة) بهدف حماية أمنها القومي ضد الته الأخطار الخارجياة.

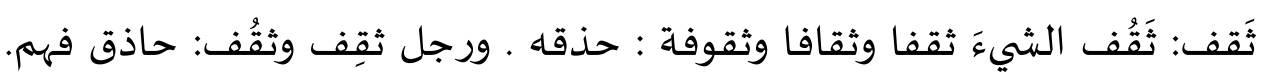

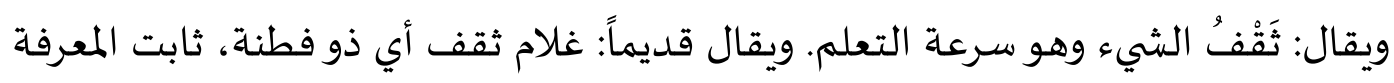

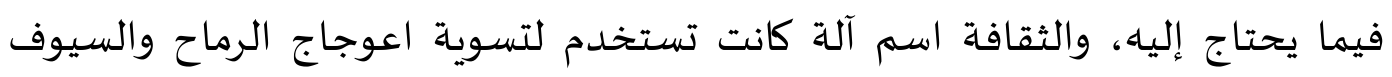

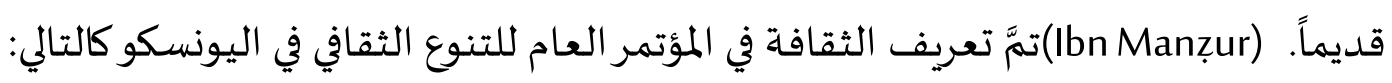

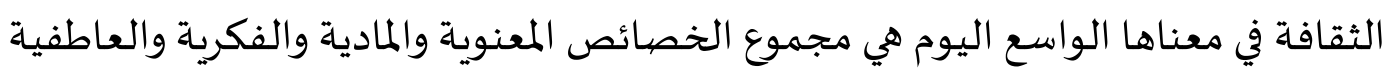

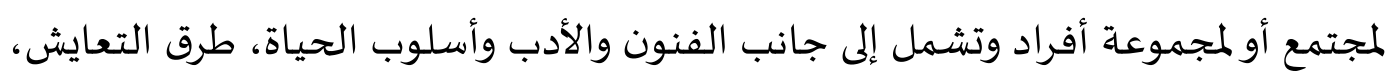

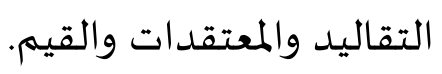

يعرّف أولي ويفر الأمن الثقافي كالتالي: "قدرة أي مجتمع على الحفاظ على هُويته

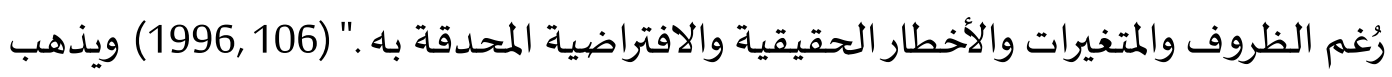

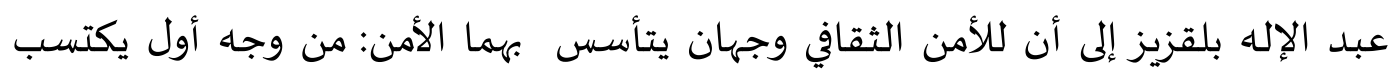




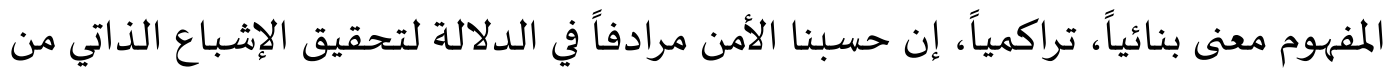

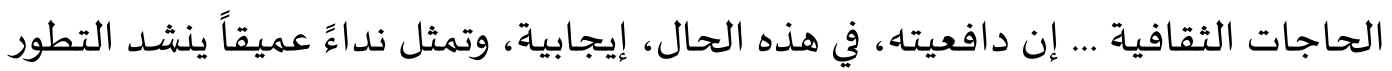

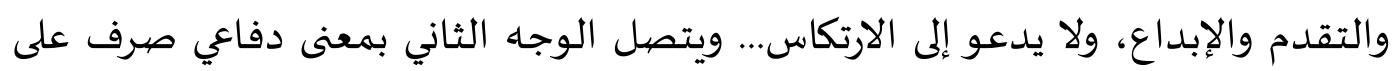

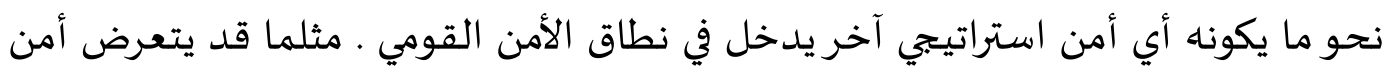

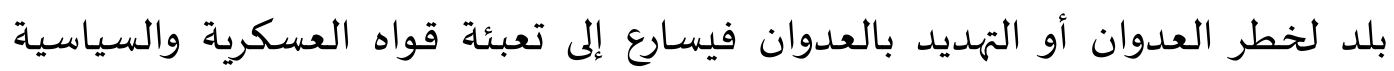

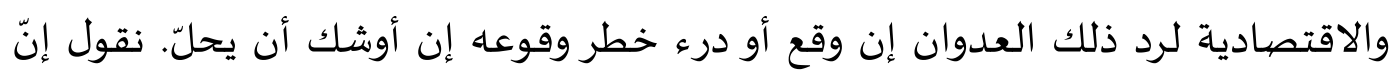

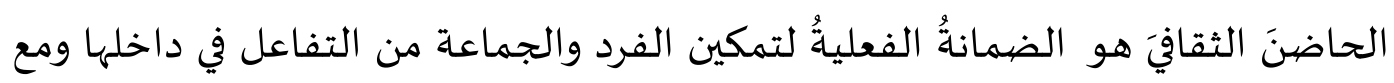
القوى المنافسة والمتآلفةِِ الأخرى.(Bilgzīz)

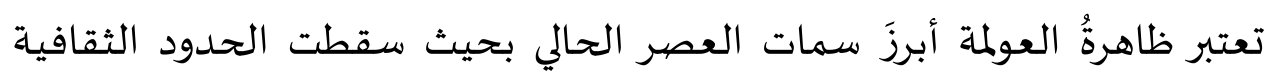

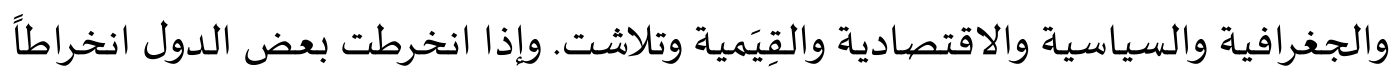

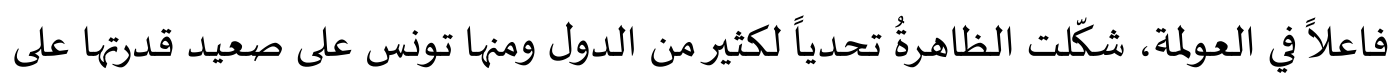
مجاههة التحديات التي أنتجتها العولمة والتي تهدّد أمنها القومي.

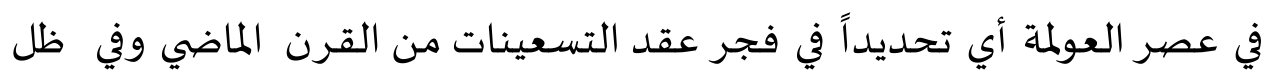

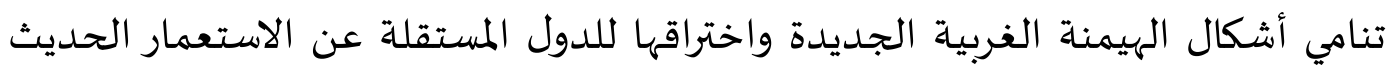

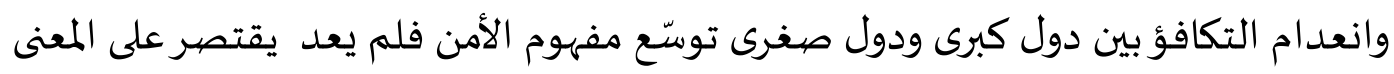

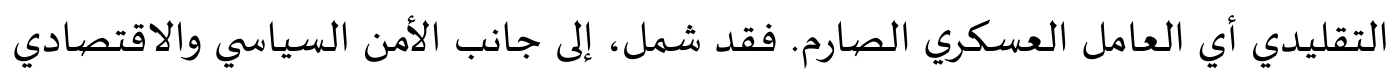

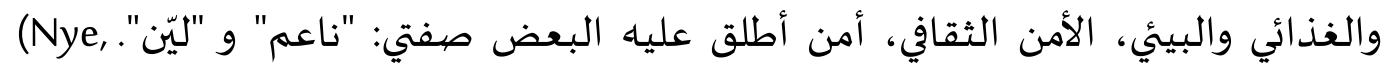
2004)

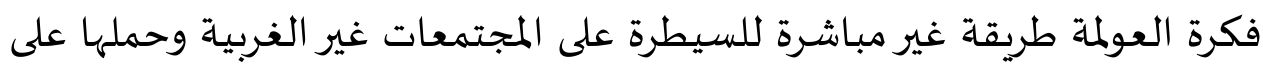

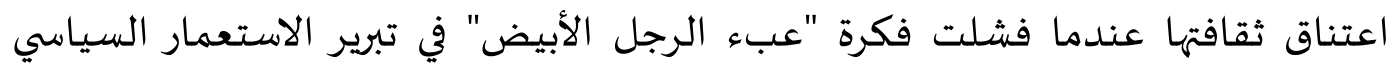

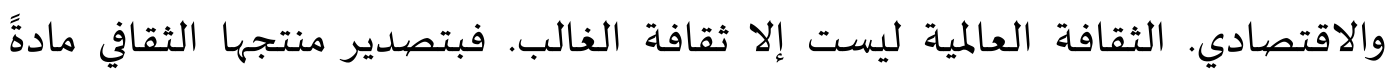

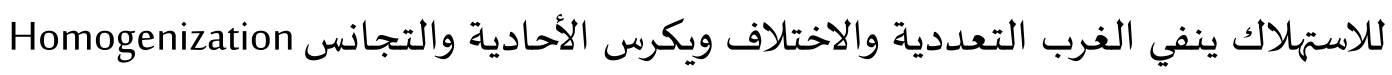

(Deneke, 2012). 
وتأتي هذه الدراسة للكشف عن مشكلات التعليم في تونس في عصر العولمة، أسبابها

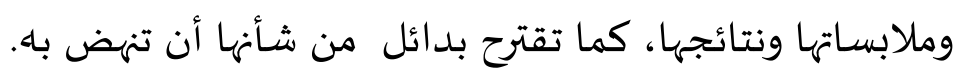

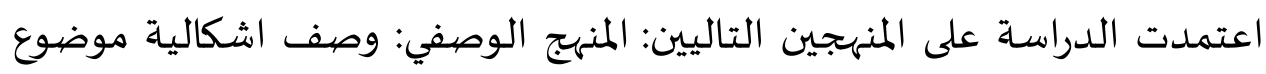

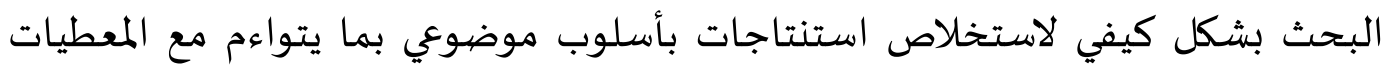

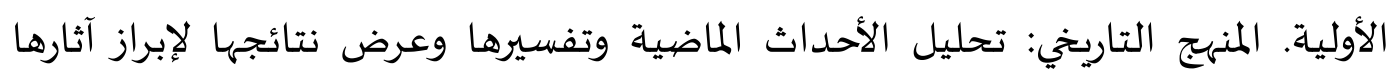
الباقية في الحاضر والمستقبل.

$$
\text { نتائج البحث ومناقشاتها }
$$

توضيح نتائج البحث أن أزمة التعليم جوانية وبرانية: الجوانية سياسية بامتياز

$$
\text { والبرانية استعمارية بحتة. }
$$

الثقافة سلطةً رمزيةً: النظريات الحديثة التهية

يمارس الغرب سلطة رمزية في بعدها الثقافي المعرفي، ممارسة تجاوزت المفهوم الفئة

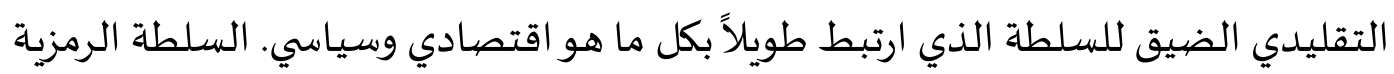

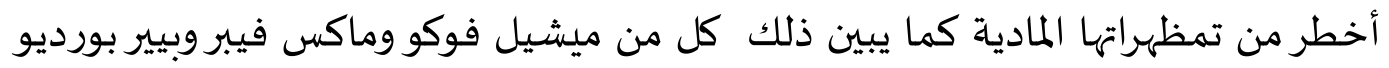

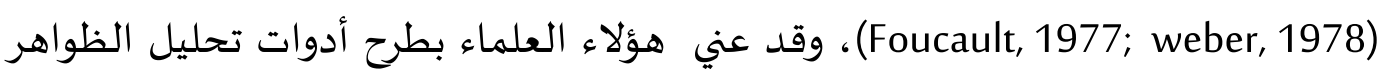

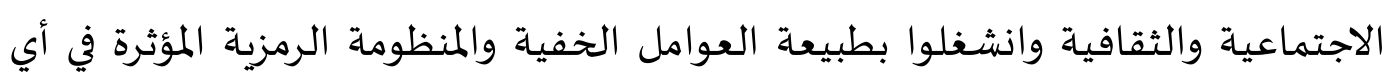

Antonio Gramsci

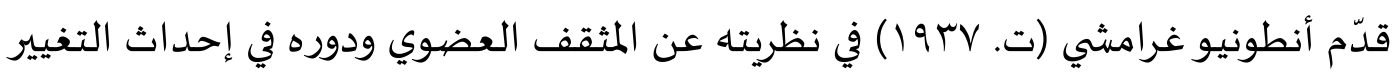
رؤياة جديدة للهيمنة السياسية والثقافية تتكون من مستويين:

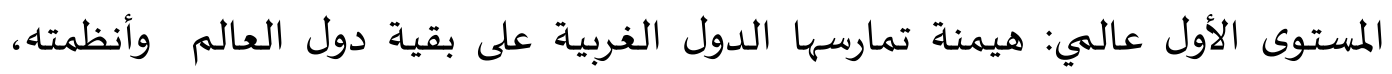

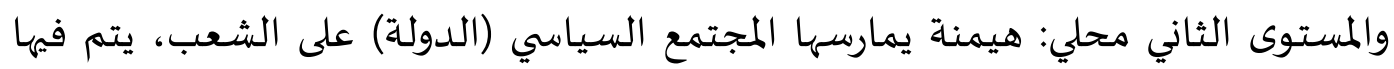

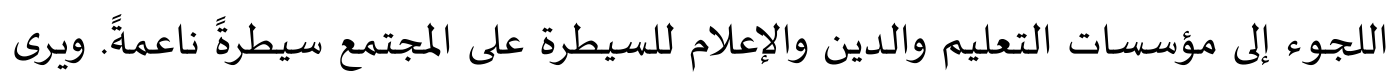


غرامشي أن التغيير يحدثه المجتمع المدني بمؤسساته ورجالاته، وخاصةً "المثقف العضوي" الذي يمثّل عماد المجتمع. (1999, 164)

\section{Pouvoir Symbolique) والسلطة الرمزية Pierre Bourdieu}

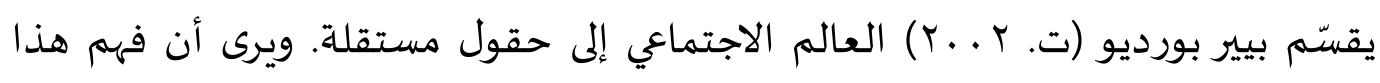

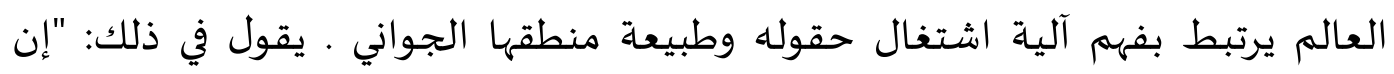

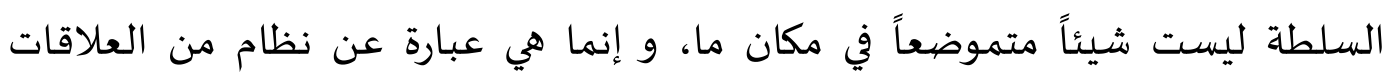

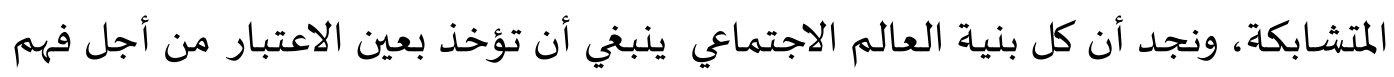
آليات الهيمنة والسيطرة." (1991,170)

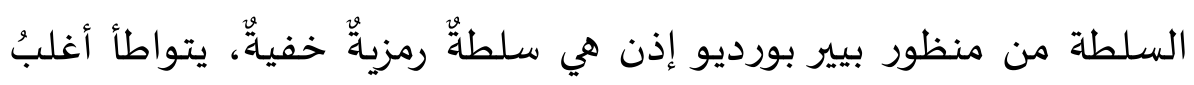

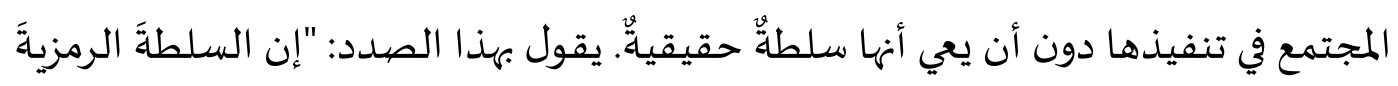

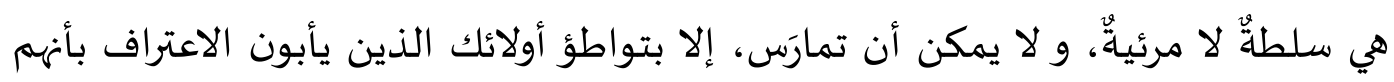

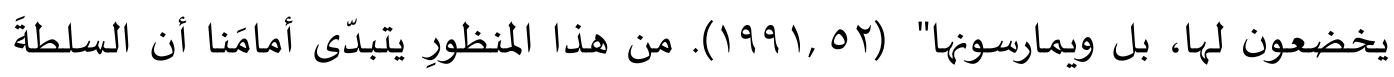

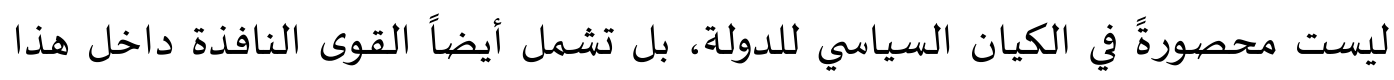
الكيان بلغتها وخطابها السائد.

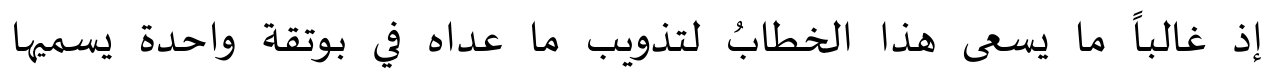

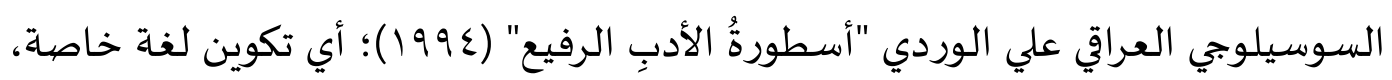

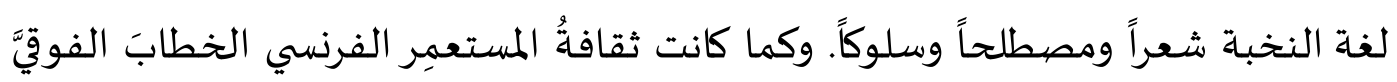
الذي تتمثّله الفئاتُ المترفةُ والتي يسميها

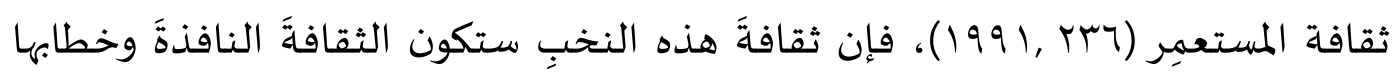

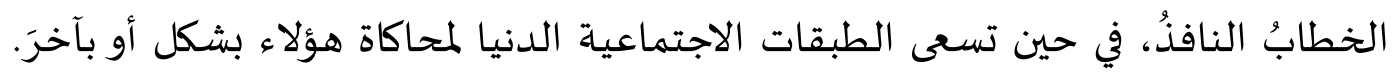

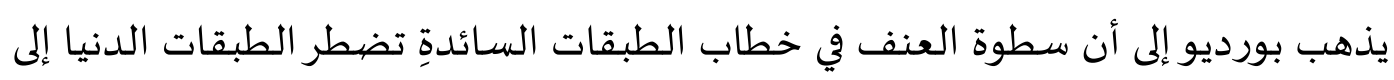
الخضوع والاعتراف بشرعية السائد، وبالتالي قبول "العنف الثقافئي" (cultural violence)،

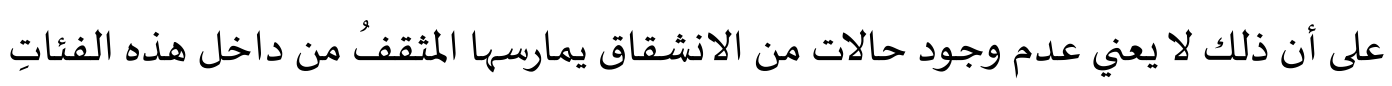

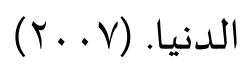


تعود محاولات الإصلاح التربوي في تونس إلى بداية القرن العشرين، وتحديداً عام

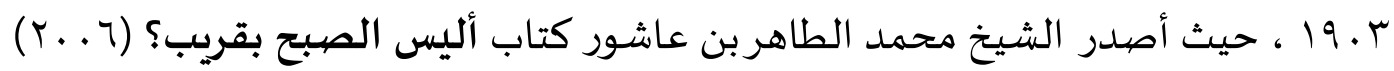

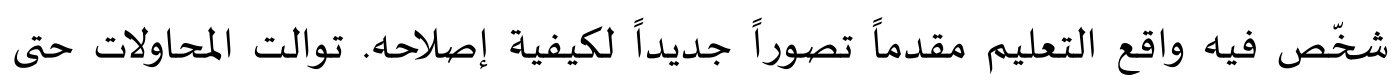

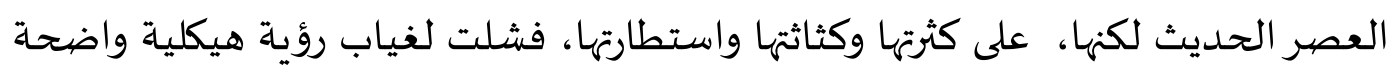

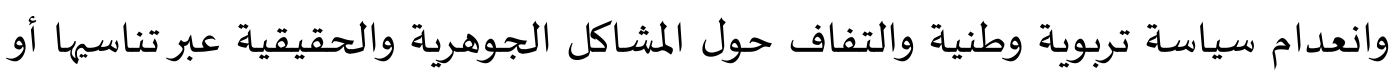

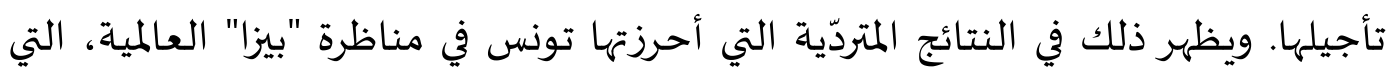

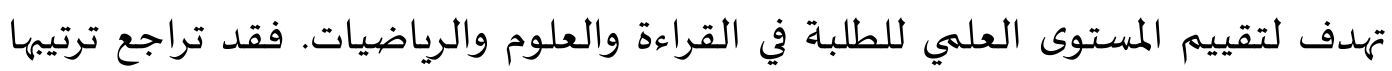

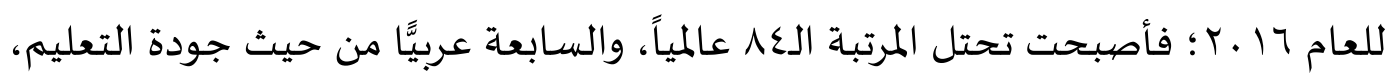

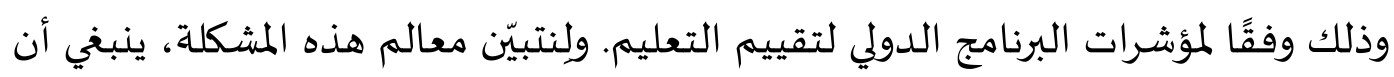
نستعيد تاريخ التعليم بعد الاستقلال. أ- التعليم بعد الاستقلال

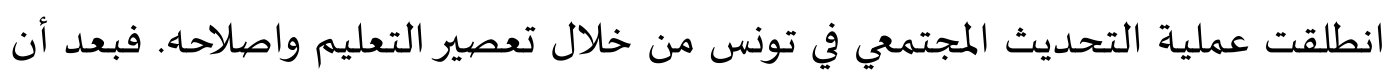

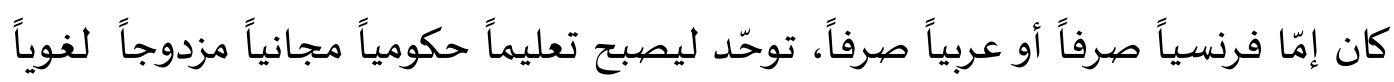

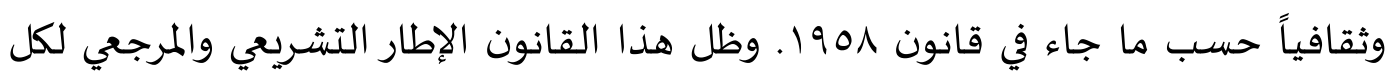

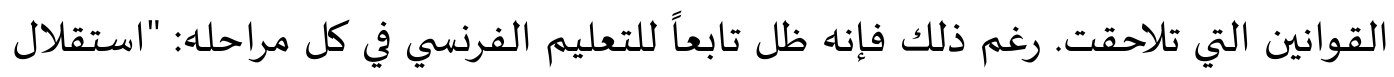

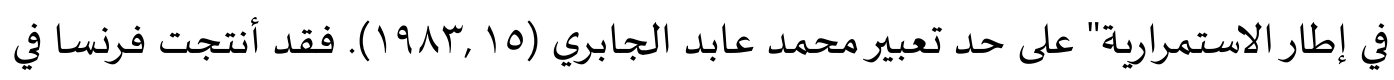

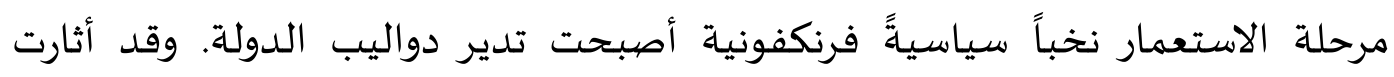

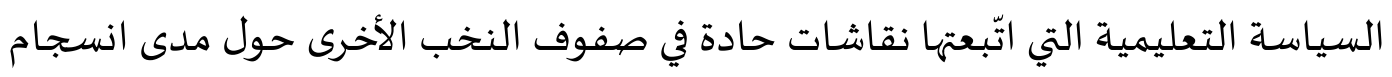

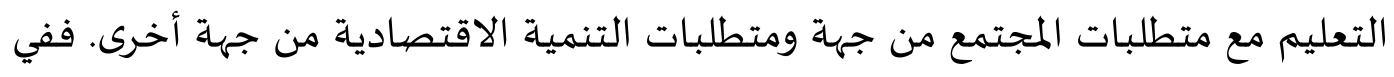

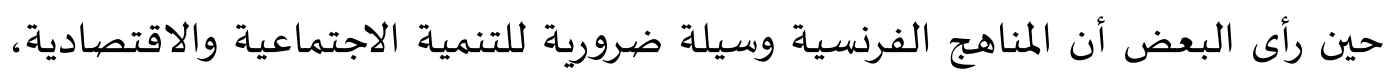

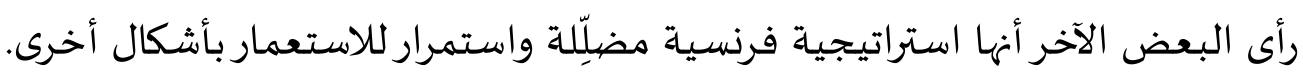

وقد مرّ التعليم في تونس منذ الاستقلال إلى الآن بثلاث مراحل: (Abno, 2018) 1: فترة الازدواجية: 1907-19VY

سعت حكومة الاستقلال بقيادة الرئيس الحبيب بورقيبة إلى إلغاء الكتاتيب والتعليم الشرعي في جامعة الزيتونة. وبرّر الرئيس ذلك في خطادة الرئ الريس بمدينة مونريال في 11 
مايو 1971 بضرورة اللحاق بركب الحضارة. ظلت العربية، كما كانت في السنوات الأخيرة

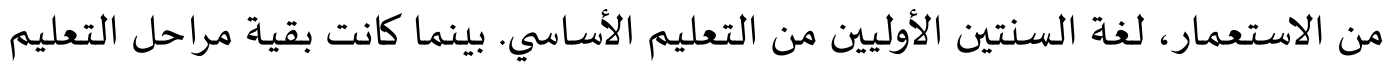

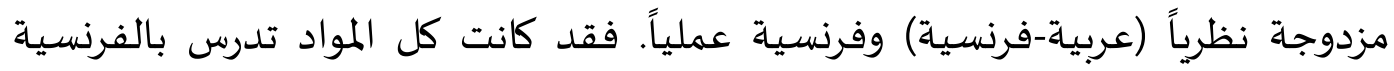
باستثناء مادتي العربية والتربية الإسلامية.

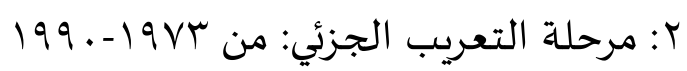

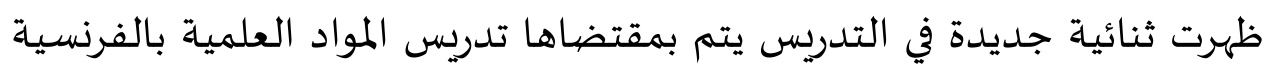

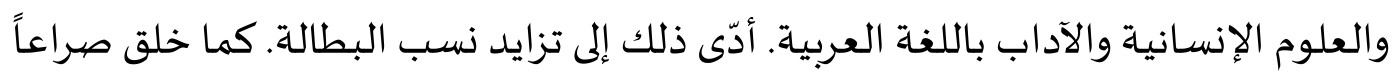

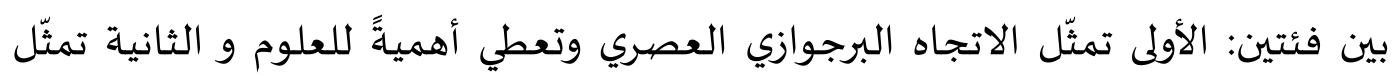

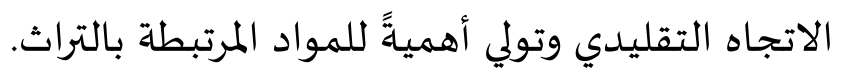

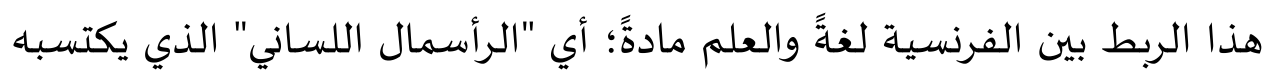

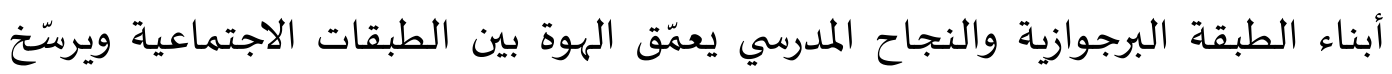

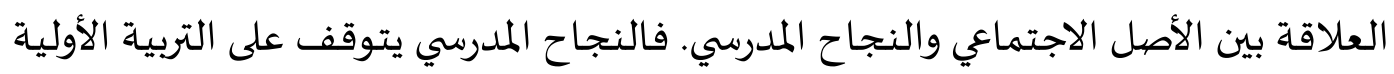

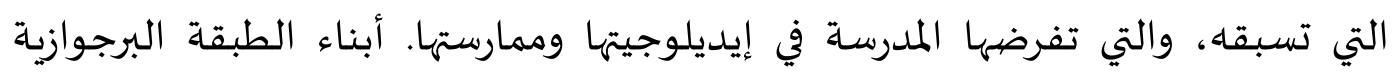

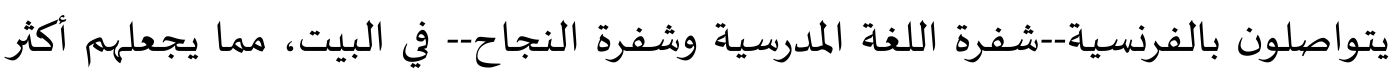

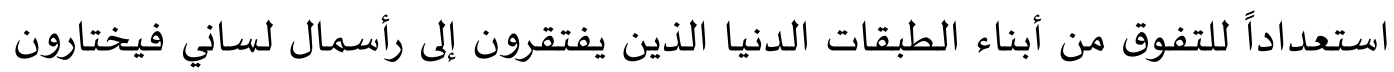

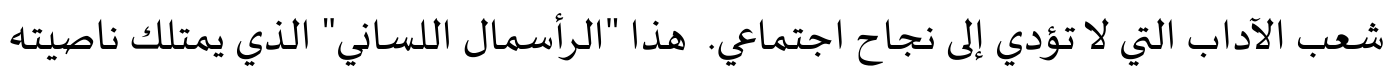

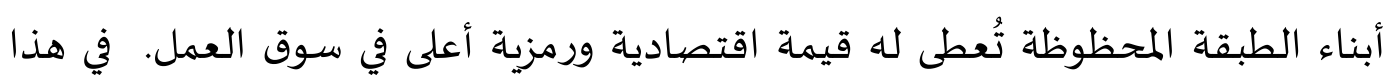

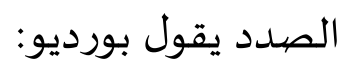

يمثّل التوزيع المتفاوت بين مختلف الطبقات الاجتماعية لِ "رأس المال اللساني" المغلّ المّل

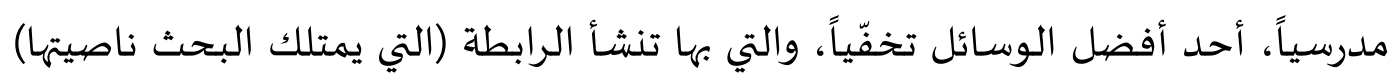

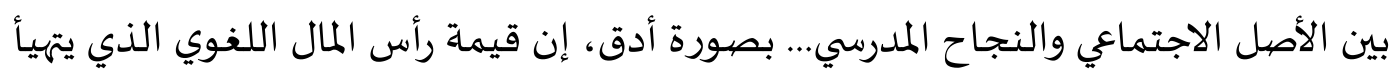

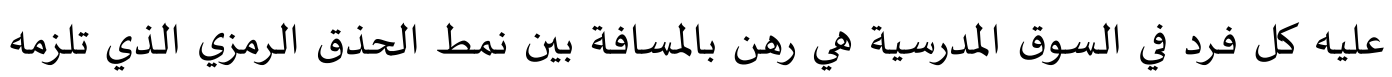

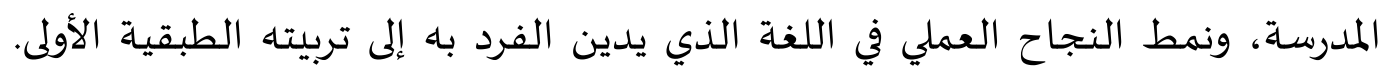

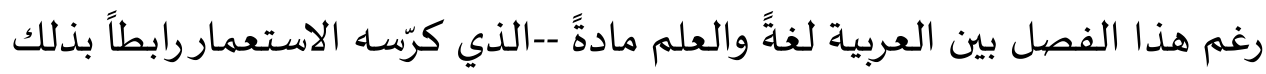

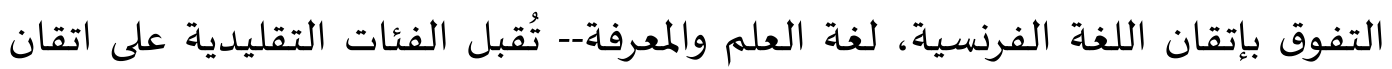


اللغة العربية وآدابها ردّاً على المستعمر وتعزيزاً لثقافتها القومية. وما يبدو صراعاً حداثيّاً.

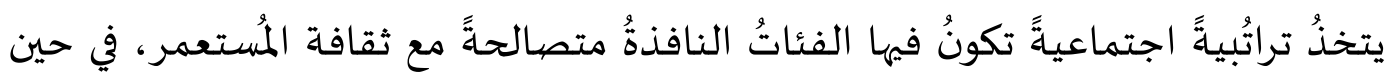

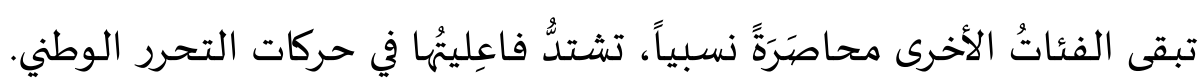

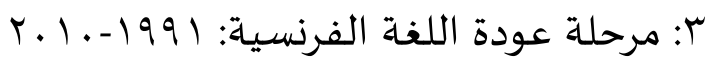
عادت اللغة الفرنسية بقوة في كل مراحل التعليم. وشذّت عن القاعدة بعض المض المواد العلمية التي أصبحت بداية من سنة 1990 تدرّس بالعربية في السنوات الثانولية الثرنية الأولى ثم بالفرنسية في بقية سنوات الثانوية وفي الجامعة.

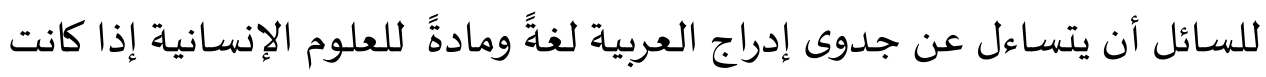

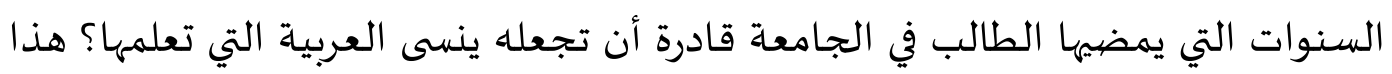

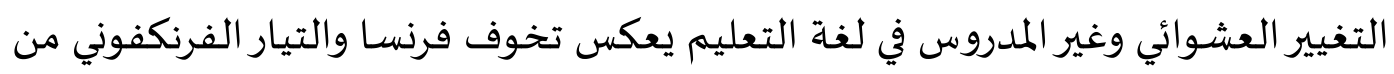

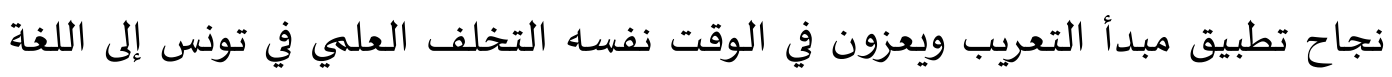

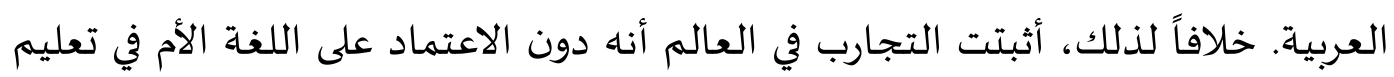

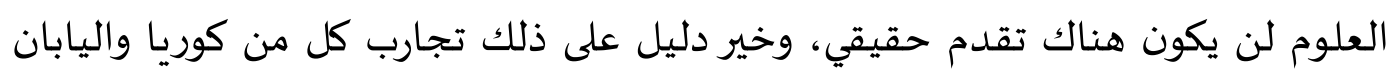

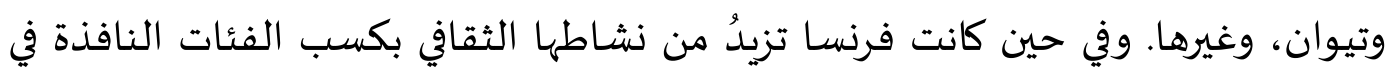

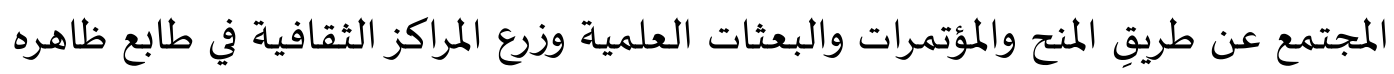

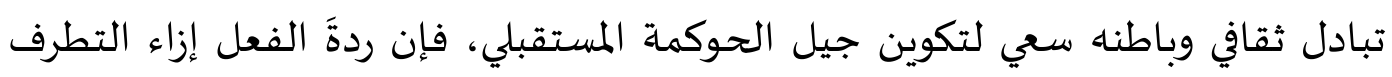

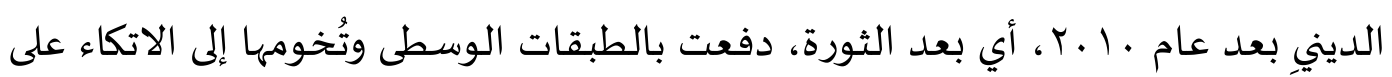

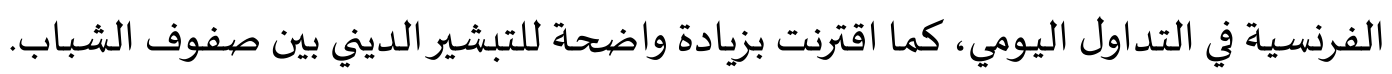

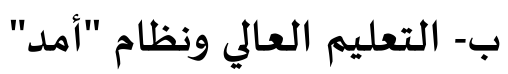

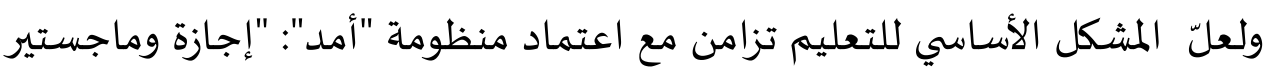

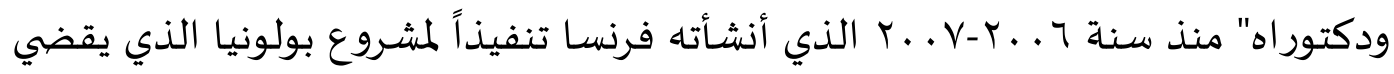

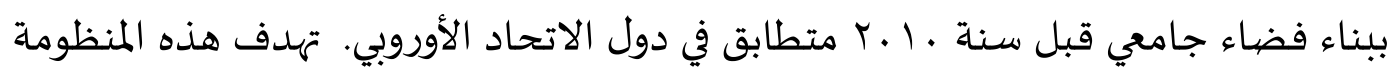

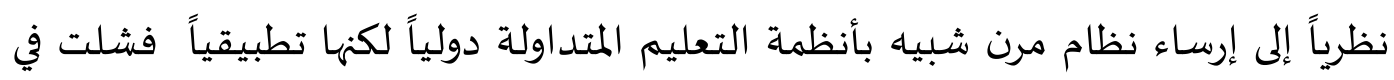

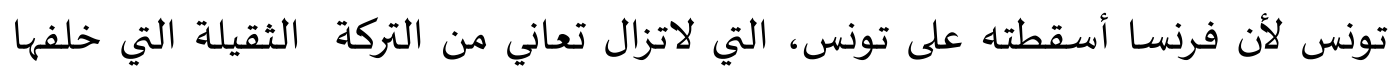

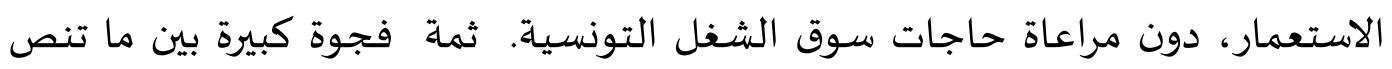


عليه القوانين المنظمة للتعليم العالي وبين واقع التعليم. ففي حين ينص القانون عدد 19

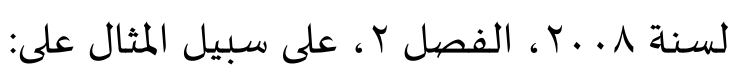

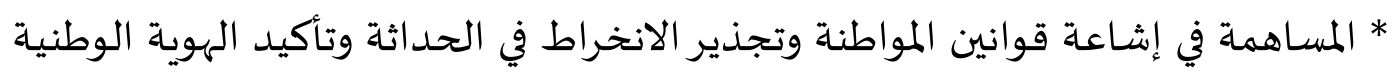

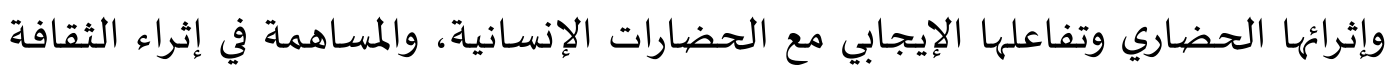

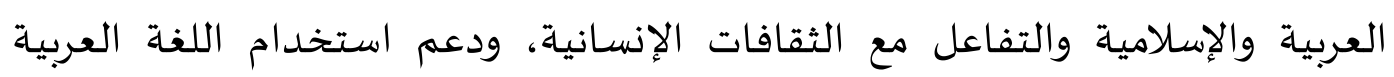
والتمكن من اللغات الأجنبية تفاعلاً مع التطورات الكونية وتنامي التبادل الفكري.

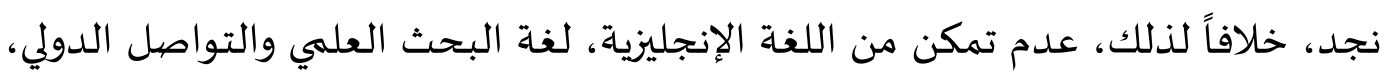

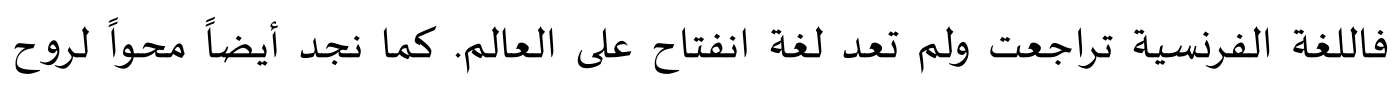

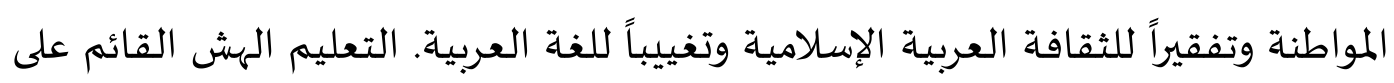

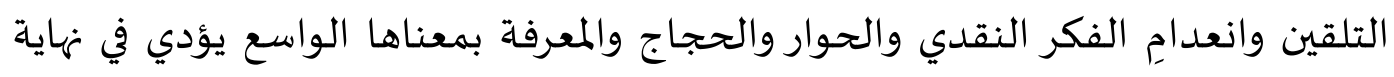

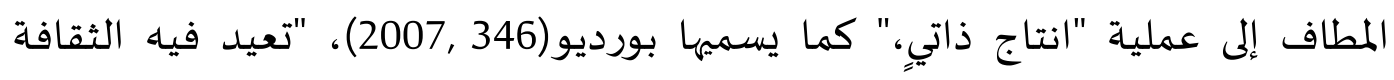

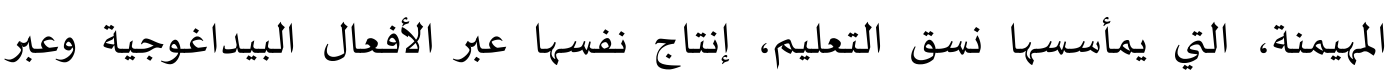

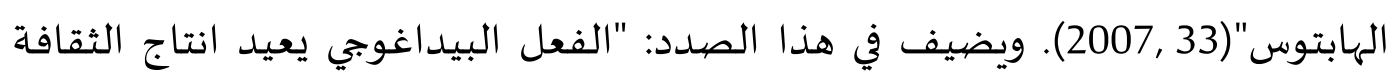

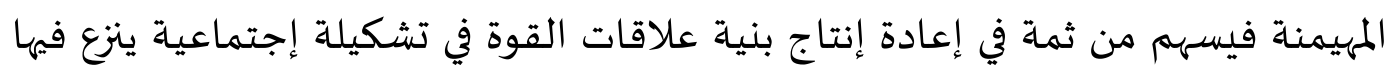

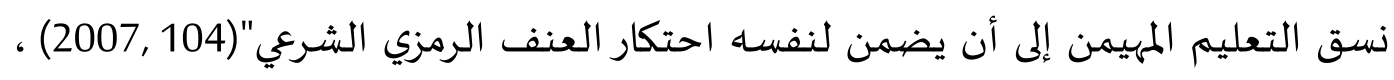

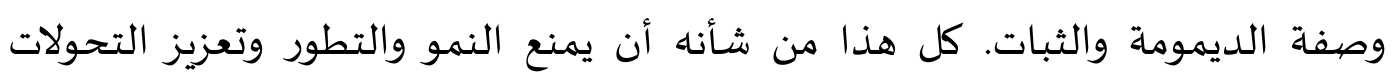
الثقافية اللازمة.

\section{تسييس التعليم: بين إقصاء واصطفاء}

عمل النظام التونسي -- ولا يزال - على توظيف نسف التهاء التعليم للحفاظ على النظام

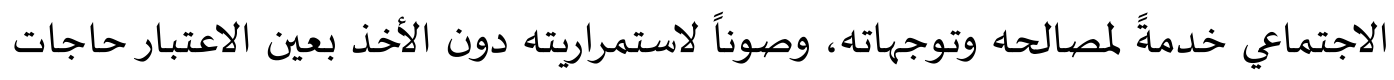

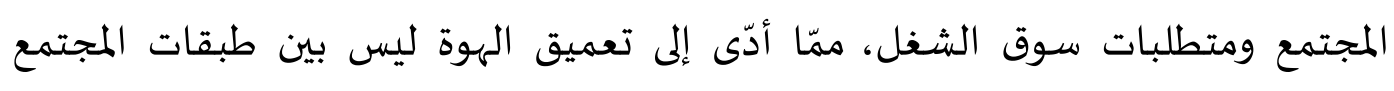

$$
\text { فحسب، بل بين الجهات أيضاً. }
$$

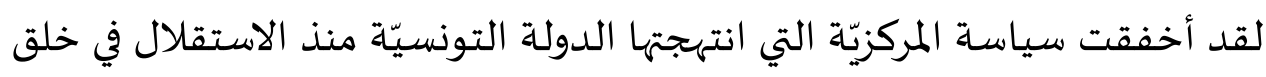

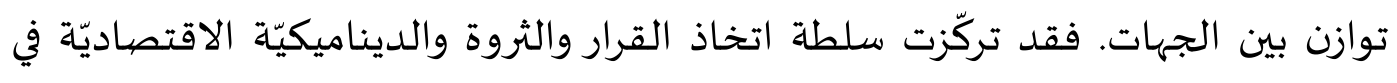

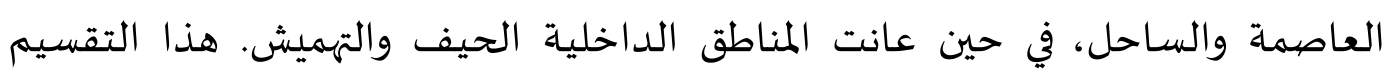


الجهويّ والإداريّ الخاضع للحسابات السياسيّة هدفه ضمان السيطرة على الجهات التي

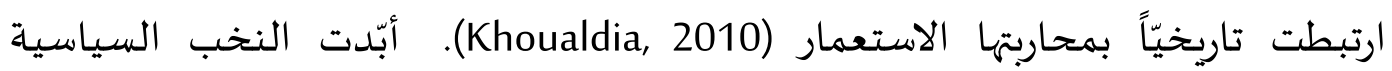

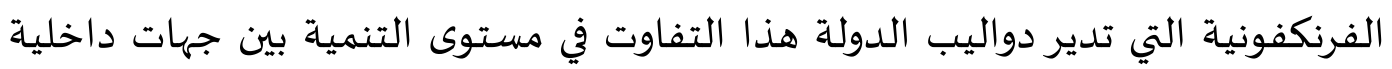

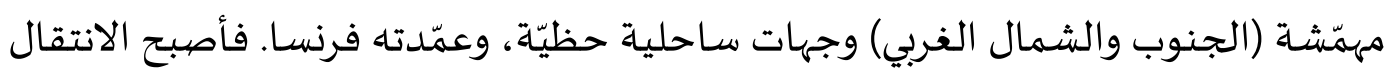

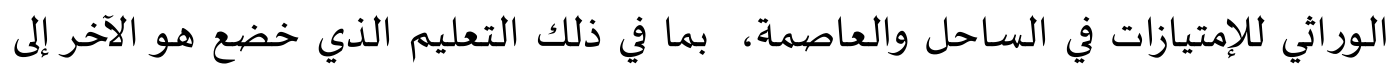

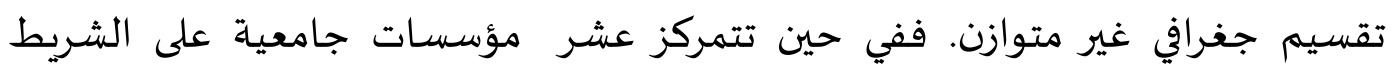

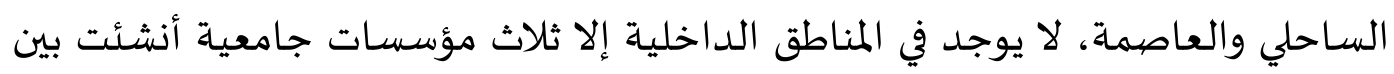

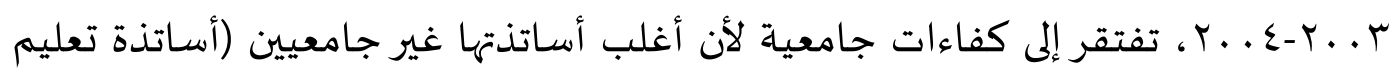

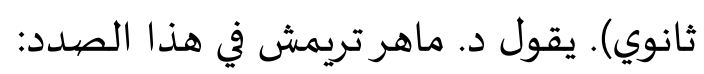

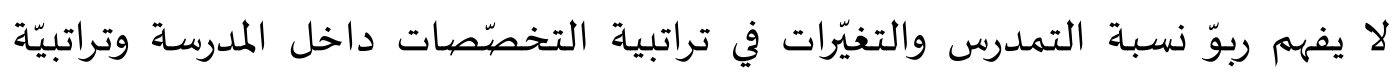

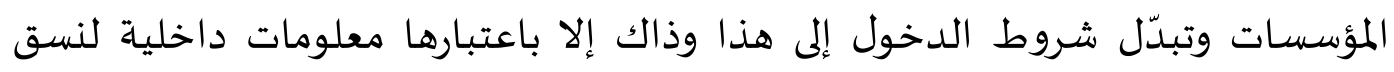

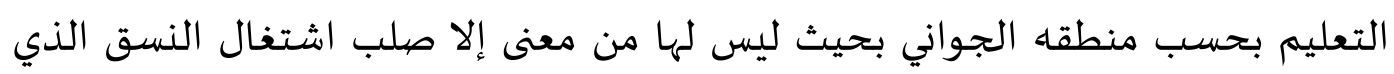

يقوم على الإقصاء والاصطفاء. (CSID, 2017)

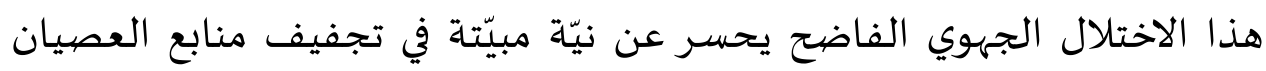

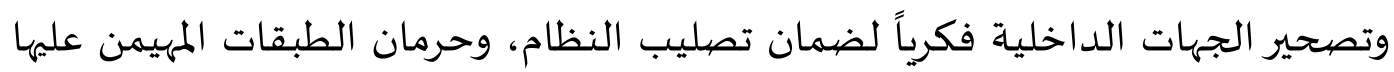

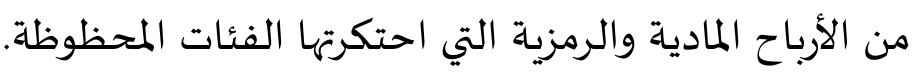

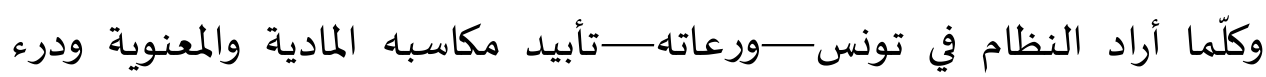

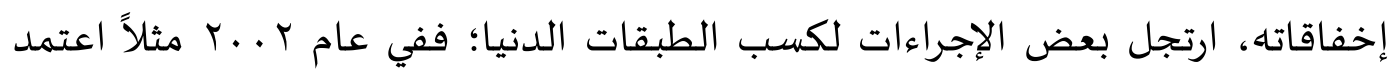

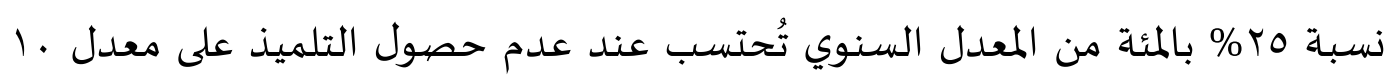

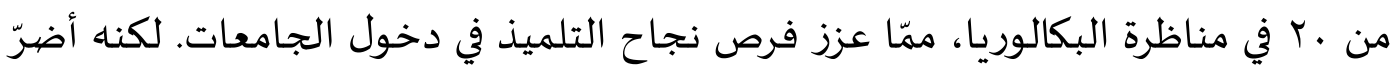

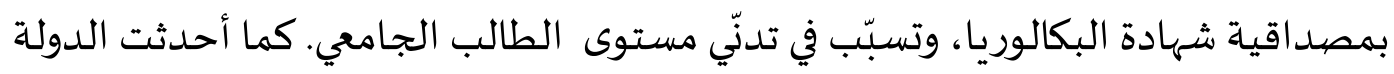

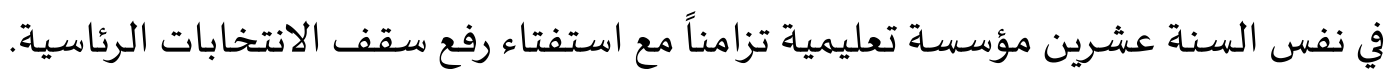

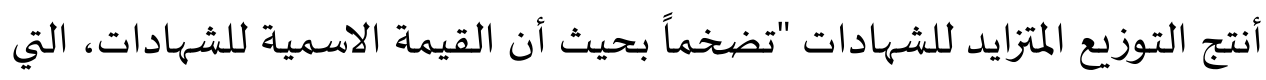

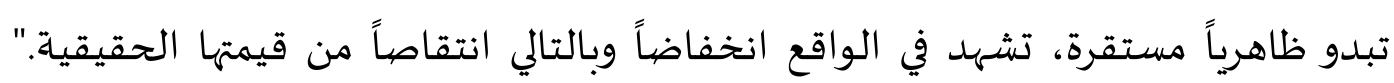
(Bazzāz, 2007, 98) 


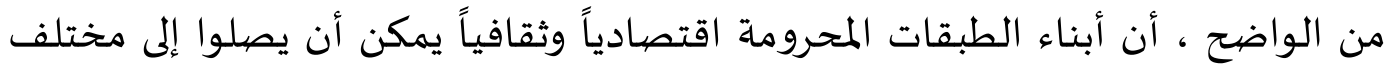

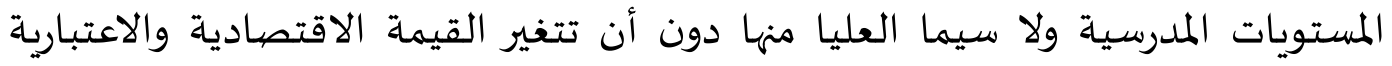

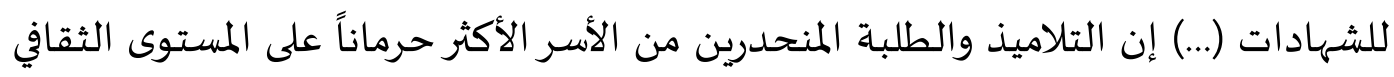

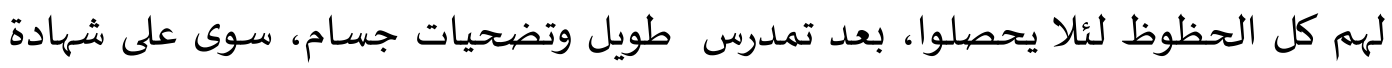
منتقصة وغير مثمنة.) (1993, 599)

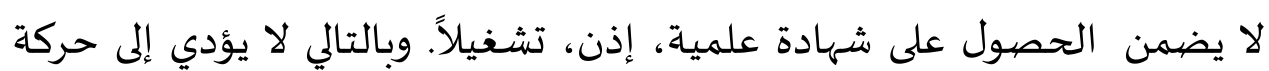

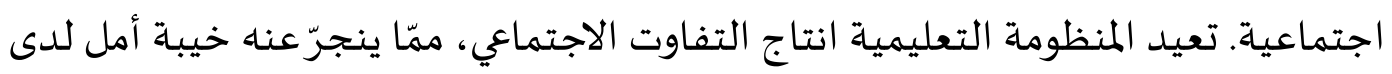

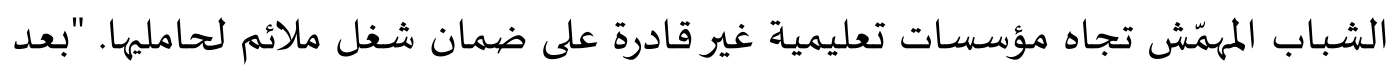

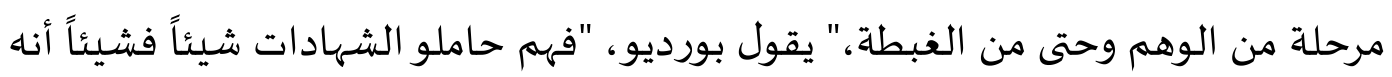

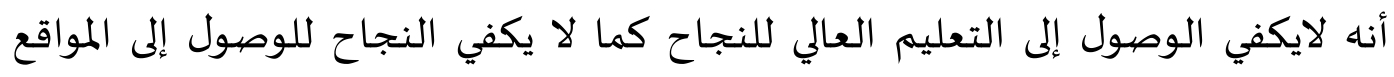

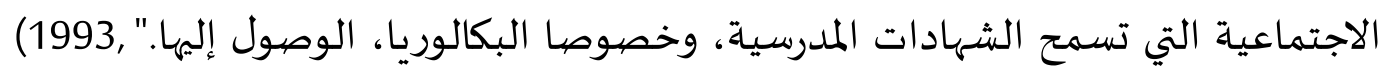

ترجم بعض الشباب العاطل عن العمل عن حالة الإحباط التي يعيشها، وعن

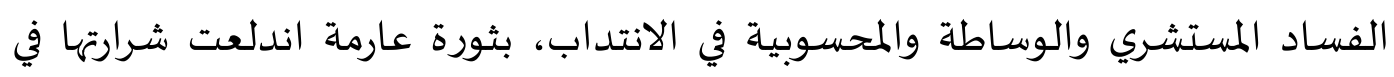

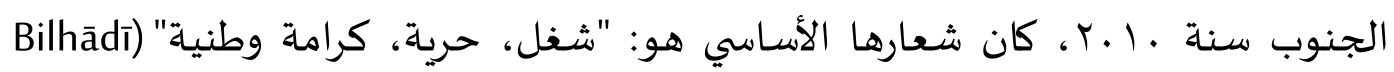

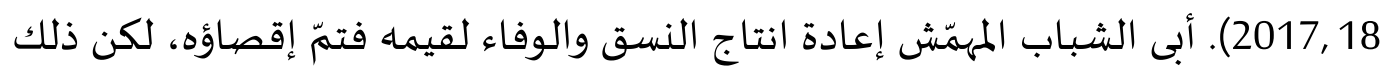

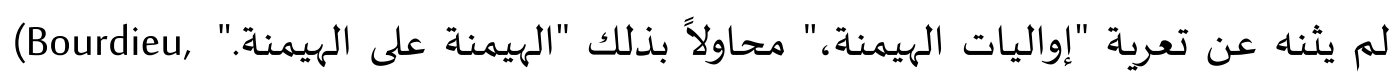
2007, 30)

يتبدّى الخلل الخطير في منظومة التعليم، أيضاً، في لفظها آلاف الشباب إلى متاهات

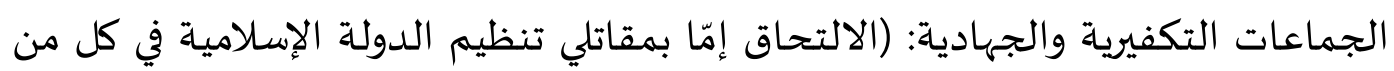

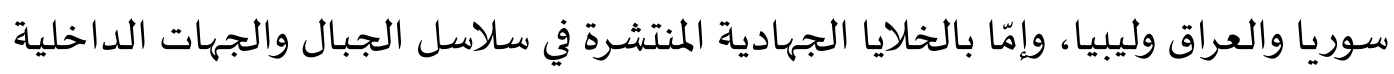
والأحياء الشعبية في تونس)، وإلى قوارب الهجرة غير الشرعية. (Al-irhāb, 2016)

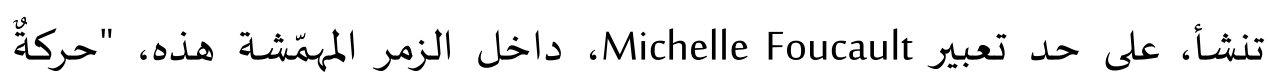

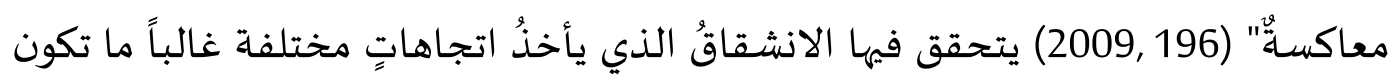

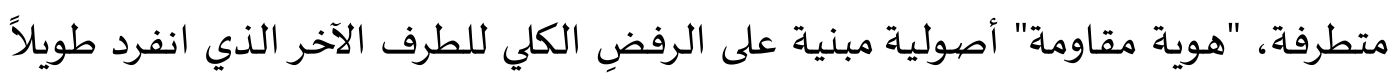

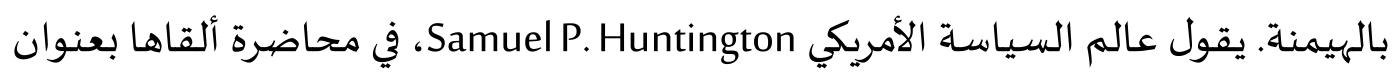


Francis (صدام الحضارات) عام 199 ردّاً على تلميذه "The Clash of Civilizations"

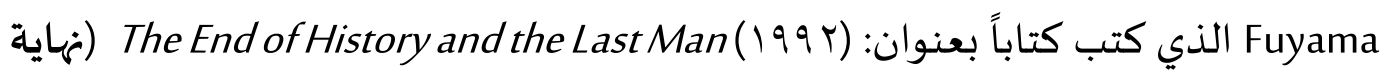

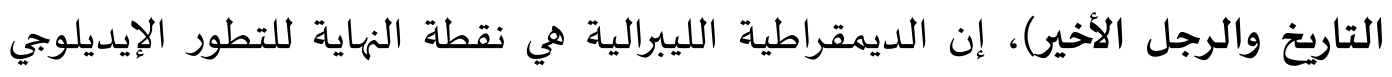
للإنسان. "تعرف الشعوبُ نفسها من خلال النسب والدين واللغة والقيم والمؤسسات الترات

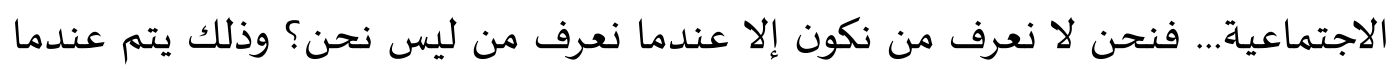
نعرف نحن ضدَّ من؟؟) (2002, 39).

التحديث والعولمة نتجت عنهما صحوة دينية كونية يطلق عليها المفكر الفرنسي جيل

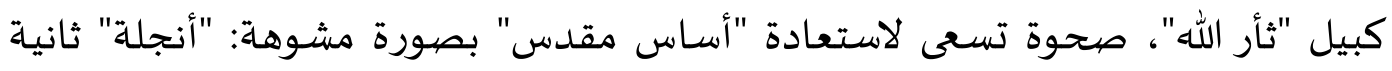

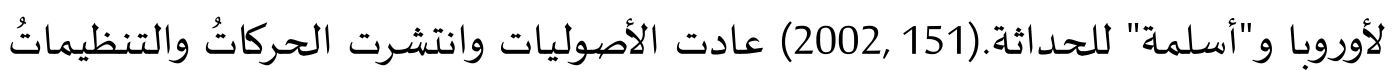

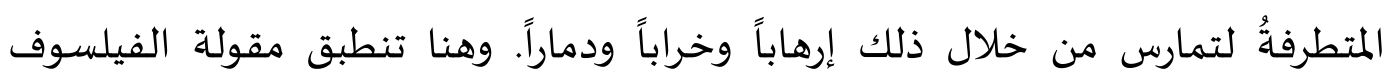
الفرنسي ريجياه دوبري: الدين فيتامين الضعفاء. (Debray, 2005)

الخاتمة

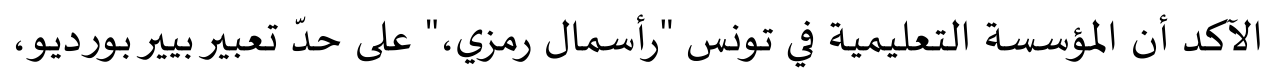

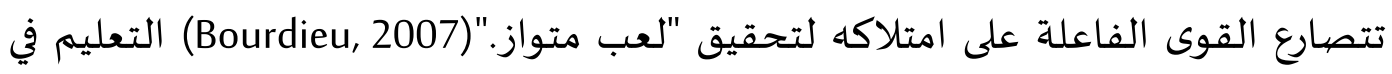

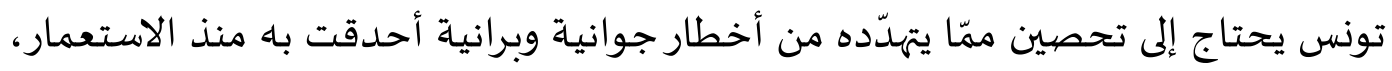

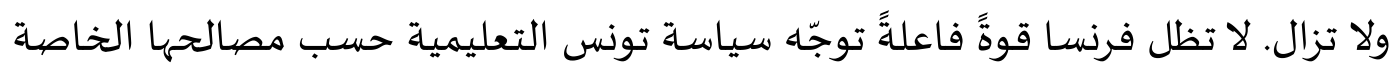

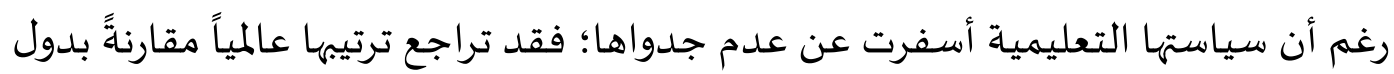

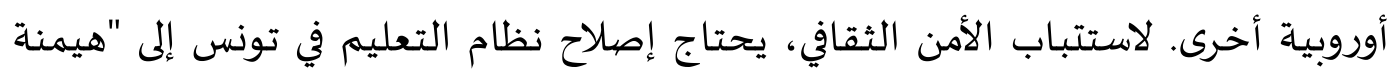

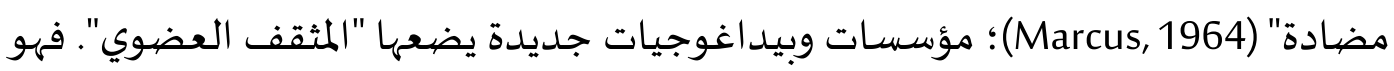

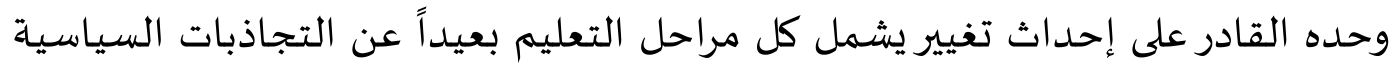

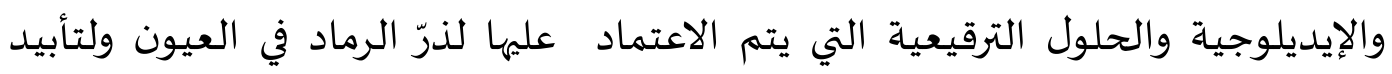

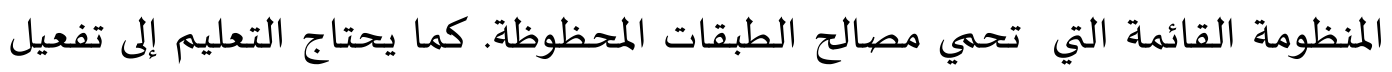

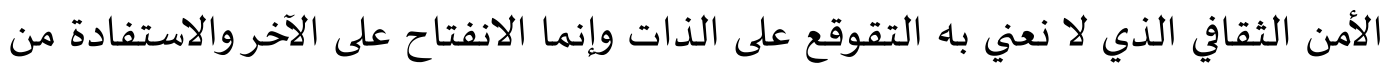

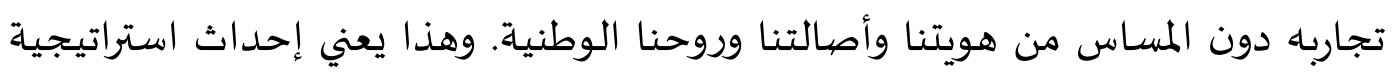

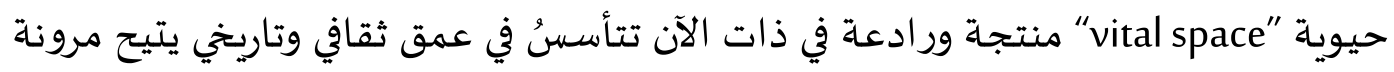

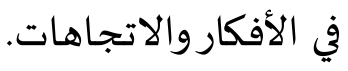


Journal of Arabic Learning

DOI: $10.18860 / \mathrm{ijazarabi.v4i1.10220}$

ISSN(print): $2620-5912$ | ISSN(onIine): $2620-5947$

ejournal.uin-malang.ac.id/index.php/ijazarabi/index | 191

\section{المراجع}

Abno, D. B. (2018, January 11). "Waraqa talkhīṣiyya 'an ishkāliyyāt iṣlāḥ al-ta 'līm al-‘āli wal-baḥth al-'ilmī fì Tūnis." http://arabic.iiit.org/. Accessed on 29/8/2020.

Al-Jābirī, M. A. (1983). Aḍwā' 'alā mushkil al-ta 'līm bil-Magrib. Al-Dār alBayḍā': Dār al-Nashr al-Maghribiyya.

Al-irhāb fì Tūnis min khilāl al-milaffāt al-qaḍāiyya. (2016, October): https://inkyfada.com/wp-content/uploads/2016/12/etude-secret.pdf. Retrieved 29/8/2020.

Al-Wardī, A. (1994). Ustūrat al-adab al-rafì . London: Dār Kūfān.

Bazzāz, A. K. (2007). 'Ilm ijtimā'‘ Pierre Bourdieu. PhD diss. Constantine: Mantūri University.

Bilgzīz, A. "Fi mafhūm al-Amn al-Thaqāfî". 'Arab 48: Accessed on 29/8/2020.

Bilhādī, U. (2017, February 16). “Al-tamyīz al-ījābī: Āliyya lil-inșāf wal-indimāj al-turābī." Al-tamyīz al-ījābī: mabda' dustūrī li-ta'zīz al-lā-marqaziyya: Ayyat āliyyāt lil-taf'īll? conference.

Bin 'Āshūr, M. A. (2006). Alyasa al-subh bi-qarīb. Tunis: Dār Suhnūn lil-Nashr wal-Tawzí.

Bourdieu, P. (1993). La Misère du Monde. Paris: Le Seuil.

. (1991). Language and Symbolic Power. Trans. Gino Raymond and Mathew Adamson. London: Polity Press.

Bourdieu, P and Passeron, J. C. (2007). I'adat al-intaj fi sabil nazariyya 'amma fi nasaq al-ta 'lim. Beirut: Al-Munazzama al-'Arabiyya lil-Tarjama.

CSID Tunisia. $\quad$ (2017, $27 \quad$ April). https://www.youtube.com/watch?v=cz6byD6fFEQ. Debray, R. (2005). Feu Sacré. Paris: Gallimard.

Deneke, W. M. (2012), Cultural Hybridization or Cultural Homogenization: The Resistance of the Others. Lap Lambert Academic Publishing.

Fanon, F. (1991). The Wretched of the Earth. Trans. Constance Farrington. New York: Grove Weidenfeld.

Foucault, M. (1977). Discipline and Punish: The Birth of the Prison. Trans. Alan Sheridan. New York: Vintage Books.

. (2009). Security, Territory, Population: Lectures at the Collège de France, 1977-1978. Ed. Arnold Davidson. London: Palgrave Macmillan.

Fuyama, F. (1992). The End of History and the Last Man. New York: The Free Press.

Gramsci, A. (1999). Selections from Prison Notebooks. Trans. Quentin Hoare and Geoffrey Nowell Smith. London: The Electric Book Company Ltd.

Huntington, S. P. (2002). The Clash of Civilizations? And the Remaking of World Order. New York: Simon and Schuster.

Ibn Manẓūr. Lisān al- 'Arab. Ed. 'Abdullāh 'Alī al-Kabīr. Cairo: Dār al-Ma'ārif. 
Journal of Arabic Learning

DOI: $10.18860 / \mathrm{ijazarabi.v4i1.10220}$

ISSN(print): $2620-5912$ | ISSN(onIine): $2620-5947$

ejournal.uin-malang.ac.id/index.php/ijazarabi/index/ $\mathbf{1 9 2}$

Khoualdia, D. (2010). Qabīlat al-Hamāmma fil-nișf al-awwal min al-qarn al- 'ishrīn (1881-1950) bayn sindān al-Ḥusayniyyīn wa miṭraqat al- Faransiyyīn. Tunis: Dunyā Brant.

Marcuse, H. (1964). One-Dimensional Man. Boston: Beacon Press.

Nye, J. (2004). Soft Power: The Means to Success in World Politics. New York: Public Affairs.

UNESCO Universal Declaration on Cultural Diversity: www.unesco.org, Retrieved 29/8/2020. Edited.

Waever, O. (1996, March). "European Security Identities," Journal of Common Market Studies, 103-132, 34 (1).

Weber, M. (1978). Economy and Society. Ed. G. Roth and C. Wittich.

Berkeley: University of California Press. 